\title{
Innovation and responsibility in education and research in Latin America
}

\section{Maria Rita Bertolozzi' ${ }^{1}$ Katia Grillo Padilha²}

Considered as a reference in nursing by the University of São Paulo (USP) and the Coordination for the Improvement of Higher Education Personnel (CAPES), in 2012, the School of Nursing of University of São Paulo (EEUSP) submitted the first interinstitutional and international Ph.D. program designated DINTER, which was approved by USP and CAPES. EEUSP is responsible for promoting DINTER and establishing the program at the Escuela de Enfermería de la Pontificia Universidad Católica (UC) de Chile. DINTER comprises three graduate programs at EEUSP: Adult Health Nursing (PROESA), Nursing (PPGE), and Nursing Management (PPGEn).

DINTER was created to train Chilean nurses at the doctoral level and to create a research network in nursing by qualifying nursing students with competence and capacity for critical reflection and integrating them within the research staff from UC and EEUSP.

EEUSP is considered a pioneer in graduate studies in nursing in Brazil and is committed to train teachers and researchers and respond to the needs of the population in Brazil. EEUSP acknowledges the national plan for graduate programs and is committed to changing the epidemiological profile and reducing the social inequalities in Brazil. Moreover, EEUSP and other teaching units in nursing have been helping to establish graduate courses in several regions of Brazil.

A joint initiative at the international level has been occurring pari passu with the development of two national DINTER programs destined to the Federal Universities of Amazonas and Amapá. The increase of the graduate programs in these regions fills a void for qualified professionals and promotes the scientific independence of these institutions.

The university, acting as a social organization, is the historically determined expression in the social sphere. The initiative from DINTER demonstrates the harmony between teaching and research and the irreducibility of knowledge. In this respect, the university aims to foster critical thinking and reflection and makes an incremental contribution to the knowledge development.

The DINTER was created as a joint effort between the graduate programs at EEUSP and UC. The enthusiasm for student training is continuous and is based on EEUSP's expertise in this level of training. This initiative is shielded from the fluctuations of shortsighted interests and allows acquaintance with the real needs of the populations of Chile and Brazil, without losing sight of the political and ideological commitment to the more vulnerable social groups.

In addition to the student training, this program aims to establish a research network in nursing focusing on the health needs of the population, primarily in Latin America. Moreover, in the future, this initiative may cross the boundaries of Latin America. The political and scientific training of the students who are participating in the DINTER program is compatible with the proposal of an interinstitutional Ph.D. program focused on training researchers who can work with intelligence and justice simultaneously to the technical skills that the nursing area requires.

DINTER comprises studies in innovative areas, aiming to create elements to restructure the knowledge already established and to promote its continuity by other researchers. Thus, it aims to encourage critical thinking; to innovate; to have a social, political, and economic impact that influences others' actions; to have the ability to solve scientific and social problems; to articulate both universal and specific actions; and to contribute to social policies and social care practices taking in account the individuals' social needs. Moreover, distinct areas of study with different theoretical and methodological approaches should be respected. These values are inherent to universities, which are represented as social institutions that present criticism and the thinking as incorporated values ${ }^{(1)}$.

Finally, it is important to acknowledge the editorial of this Journal(2), in which Professor Lilian Ferrer Lagunas, Director of Graduate Studies and International Relations at the School of Nursing of the Pontificia Universidad Católica de Chile, points out the challenges of globalization for the development of health care and nursing. She particularly indicated that one of the challenges of globalization is to belong to a global community and emphasized that the respect to the social and cultural differences between both countries and to the team work are important values when conducting research aimed fostering the scientific development and the quality of the health care and nursing.

Therefore, DINTER meets these expectations by pursuing knowledge with theoretical and methodological rigor, by respecting the local customs and social identities of the countries involved, and by being genuinely interested in spreading the knowledge through high-quality studies, such as through the Journal of the School of Nursing from USP.

${ }^{1}$ Associate Professor, Department of Community Health Nursing, School of Nursing, University of São Paulo. Chairman of Graduate Studies at the School of Nursing at the University of Sao Paulo (Escola de Enfermagem da Universidade de Sao Paulo-EEUSP), São Paulo, SP, Brazil. mrbertol@usp.br ${ }^{2}$ Tenured Professor, Department of Medical-Surgical Nursing, EEUSP, São Paulo, SP, Brazil. Coordinator of the Interinstitutional and International Ph.D. program (Doutoramento Internacional_DINTER) at the EE/PUC of Chile. kgpadilh@usp.br 


\section{References}

1. Chauí M. Escritos sobre a universidade. São Paulo: Ed. UNESP; 2001.

2. Lagunas LF. Internacionalización: nuevos desafíos para el desarrollo de la ciencia del cuidado en salud y enfermería [editorial]. Rev Esc Enferm USP. 2013;47(5):1013. 